\title{
Os paradigmas na teoria de Egon G. Guba e Yvonna S. Lincoln (1994): a multirreferencialidade nas teses de doutorado em educação da UNISSINOS (2013 a
}

\section{8)}

\author{
The paradigms according to Egon G. Guba and Yvonna S. Lincoln's theory (1994): the multi- \\ referentiality in the doctorate program ate the college of education at UNISINOS university (from
}

2013 to 2018)

Los paradigmas en la teoría de Egon G. Guba e Yvonna S. Lincoln (1994): a multirreferencialidad en las tesis de doctorado de la UNISINOS (2013 a 2018)

Recebido: 29/12/2021 | Revisado: 07/01/2022 | Aceito: 12/01/2022| Publicado: 14/01/2022

Flávia Aguiar Cabral Furtado Pinto
ORCID: https://orcid.org/0000-0001-5514-6945
Universidade Estadual do Ceará, Brasil
E-mail: flavia.aguiar.cabral @ gmail.com
Ana Paula Martins Albuquerque
ORCID: https://orcid.org/0000-0002-9655-4547
Universidade Estadual do Ceará, Brasil
E-mail: paulamartinsalbuquerque @ gmail.com
Camila Maria Rodrigues
ORCID: https://orcid.org/0000-0003-4012-7121
Universidade Estadual do Ceará, Brasil
E-mail: camilamaria.rodrigues@ gmail.com
Myrcea Santiago dos Santos Harvey
ORCID: https://orcid.org/000-0003-3973-9446
Universidade Estadual do Ceará, Brasil
E-mail: myrceaharvey @ gmail.com

\begin{abstract}
Resumo
Os paradigmas de pesquisa são compreendidos por autores como Khun (1970), Creswell (2010) e Guba e Lincoln (1994), como um conjunto de crenças que orientam a atuação dos pesquisadores a partir das questões ontológicas, axiológicas, epistemológicas e metodológicas que demonstram suas concepções de mundo, razão pela qual é relevante descobrir quais delas atualmente aparecem nas pesquisas referentes às ciências humanas e sociais. O objetivo da presente pesquisa, foi analisar, a partir da concepção de Guba e Lincoln (1994), a presença dos paradigmas de pesquisa nas teses de doutorado do Programa de Pós-Graduação Stricto Sensu da UNISINOS, no período compreendido entre 2013 a 2018. Foi realizada pesquisa exploratória e descritiva, de natureza mista, considerando as necessidades metodológicas tanto para a fase de mapeamento das teses defendidas pelos estudantes do Programa de Pós-graduação Stricto Sensu em Educação da UNISINOS no período mencionado, quanto na análise dos paradigmas presentes nas teses. Como principal resultado, destaca-se que a tendência nas pesquisas em educação é a adoção da multireferencialidade e do pragmatismo, quanto à possibilidade de mesclar diferentes paradigmas de pesquisa. Os pesquisadores, de forma geral, não demonstraram, pelo menos expressamente, a preocupação apresentada por Guba e Lincoln (1994) de analisar a compatibilidade axiológica entre diferentes paradigmas para fins de comensurabilidade. Observou-se a predominância de paradigmas classificados, por Guba e Lincoln (1994), como alternativos, indicando que as pesquisas nas ciências humanas e sociais se libertaram, finalmente, do positivismo como elemento essencial para o rigor e a cientificidade das pesquisas científicas.
\end{abstract}

Palavras-chave: Paradigmas; Multirreferencialidade; Educação; Ensino.

\begin{abstract}
The research paradigms are understood by authors such as Kuhn (1970), Creswell (2010) and Guba and Lincoln (1994), as a set of beliefs that guide researchers' actions based on the ontological, axiological, epistemological and methodological issues that demonstrate their conceptions of the world, which is why it is relevant to find out which one of these currently appear in studies on the human and social sciences. The objective of the present research, therefore, was to analyze, based on the conception of Guba and Lincoln (1994), the presence of research paradigms in the doctoral theses of the UNISINOS University's Stricto Sensu Program, from 2013 to 2018. For this, an exploratory and
\end{abstract}


descriptive research of mixed nature was carried out, since both the quantitative and qualitative methods were used. Firstly, the quantitative was used when mapping the amount of theses defended by the students of the Stricto Sensu Program in Education. Secondly, the qualitative method employed can be clearly identified when the theses were analyzed. As a main result, it is noteworthy that the trend in educational research is the adoption of multi-referentiality and pragmatism, as to the possibility of merging different research paradigms. The researchers, in general, did not demonstrate, at least expressly, the concern presented by Guba and Lincoln (1994) to analyze the axiological compatibility between different paradigms for commensurability purposes. Moreover, there was a predominance of paradigms classified by Guba and Lincoln (1994) as alternative, indicating that research in human and social sciences has finally freed itself from positivism as an essential element for the rigor and scientificity of scientific research.

Keywords: Paradigms; Multi-Referentiality; Education; Teaching.

\section{Resumen}

Los paradigmas de las pesquisas son comprendidos por los autores Khun (1970), Creswell (2010), Guba y Lincoln (1994), como un conjunto de creencias que guían la actuación de los investigadores desde las cuestiones ontológicas, axiológicas, epistemológicas y metodológicas que demuestran sus concepciones del mundo, razón por la cual es relevante descubrir que investigaciones aparecen actualmente en las Ciencias Humanas y Sociales. El propósito de este trabajo es analizar desde la concepción de Guba y Lincoln (1994), del periodo de 2013 hasta 2018, la presencia de los paradigmas en las investigaciones en las tesis de doctorado del programa de Posgraduación en Educación Stricto Sensu de la UNISINOS. Se realizó una investigación exploratoria y descriptiva, de carácter mixto, considerando las necesidades metodológicas tanto para la fase de mapeo de las tesis defendidas por los estudiantes en el periodo mencionado como para la fase de análisis de los paradigmas presentes em las tesis. Lo principal resultado, destacase que hay una tendencia en las investigaciones en Educación que es la adopción de la multireferencialidad y el pragmatismo cuanto la posibilidad de mezclar diferentes paradigmas de investigaciones. Los investigadores no tuvieron la misma preocupación formulada por Guba y Lincoln (1994), en analizar la compatibilidad axiológica entre diferentes para fines de conmensurabilidad. Además, se observó la predominancia de paradigmas clasificados por Guba y Lincoln (1994) como alternativos, indicando que las investigaciones en las Ciencias Humanas y Sociales se libertaron finalmente del positivismo como elemento esencial para el rigor y cientificidad de las investigaciones científicas.

Palabras clave: Paradigmas; Multireferencialidad; Educación; Enseñanza.

\section{Introdução}

Durante séculos da história da ciência, a concepção positivista, com sua compreensão da realidade como um dado pressuposto, passível de total apreensão pelo pesquisador, com métodos quantitativos, objetivos e neutros de pesquisa, predominou, principalmente nas chamadas ciências "duras" como a matemática, a física, bem como as relacionadas à área da saúde, por exemplo. No entanto, absorver a realidade de forma plena mostrou-se, com o passar do tempo, impossível.

Ora, por mais que os resultados de uma análise possam ser generalizados para abranger uma ampla gama de situações, sempre haverá inconsistências decorrentes da natureza dos fenômenos ou da própria incompletude do pesquisador. Em razão disso, importante passo dado na ciência, foi o surgimento da concepção pós-positivista que passou a assumir que a realidade não é apreensível em sua totalidade, nem neutra e, muito menos, objetiva como defendiam (e ainda defendem) os cientistas positivistas. Contudo, ainda hoje, os elementos caracterizadores do positivismo são considerados, por muitos pesquisadores, como critérios essenciais para o rigor e à cientificidade das pesquisas.

Nas ciências humanas e sociais não foi diferente. De forma geral, elas também adotaram o positivismo e o póspositivismo com o intuito de atribuir um caráter mais científico às pesquisas, esforçando-se, muitas vezes, para enquadrar a realidade em metodologias quantitativas, objetivas e neutras. Entretanto, essas concepções revelaram-se cada vez mais inviáveis de serem adotadas de forma pura nas ciências humanas e sociais, uma vez que a complexidade das relações interpessoais e dos seres humanos com a natureza não são passíveis de apreensão por métodos demasiadamente objetivos e impessoais de pesquisa. A consequência natural desse cenário foi, inevitavelmente, o nascimento de concepções alternativas de ciência como, por exemplo, a Teoria Crítica e o Construtivismo.

Assim, quando a Teoria Crítica surgiu, a realidade passou a ser compreendida, não como um dado pressuposto, mas como um conceito fictício, criado pelos detentores do poder, a partir de fatores sociais, culturais, econômicos, éticos e de gênero. Eis uma acepção de verdade cristalizada que os adeptos desse paradigma de pesquisa se esforçam para desconstruir. Em relação 
aos métodos, a pesquisa qualitativa ganhou bastante destaque, na medida em que passou a permitir a análise de todos os vieses que envolvem os participantes. O objetivo não é mais a neutralidade e a generalização, e sim a busca de realidades paralelas não reveladas. Sobre o avanço das teorias investigativas Neto (2020, p. 315) nos orienta a refletir acerca de que

[...]a teoria das tradições de pesquisa não é simplesmente uma teoria sobre a sucessão de teorias ou modelos de investigação de modo a estabelecer critérios de estabilidade e progresso uniformemente aplicáveis às diversas teorizações ou modelos de pesquisa, sendo mais propriamente uma dialética das tradições de pesquisa racional, uma vez que põe em confronto as diversas compreensões sobre a natureza e a estrutura do inquérito racional historicamente articuladas em tradições, consideradas segundo suas próprias pressuposições e critérios internos, em busca de soluções que lhes transcendam os limites iniciais em vista de estabelecer uma perspectiva cognitivamente adequada.

Os defensores do Construtivismo, por sua vez, também não compreendem a realidade como preexistente. Para eles, as realidades são múltiplas e mutáveis, criadas com base em vivências individuais ou coletivas. O objetivismo e a neutralidade, da mesma forma, não são adotados pelos adeptos desse paradigma como necessários ao rigor e cientificidade da pesquisa. A verdade é relativa e influenciada pelo olhar do pesquisador, como também dos pesquisados. Os métodos qualitativos consolidam-se, finalmente, como essenciais para possibilitar uma maior aproximação entre o investigador e o objeto de pesquisa. Assim, concordamos com Sandes e Silva (2020) quando os autores defendem que a revolução científica vai além de um paradigma científico, inserindo-se também como um paradigma social, uma vez que se relaciona diretamente com a concepção das relações sobre este último.

É bem verdade que essas diversas concepções de ciência receberam várias denominações e classificações de pesquisadores ao longo do tempo. Creswell (2010), por exemplo, as chamou de "concepções filosóficas". Mas, foram os pesquisadores Egon et al. (1994) que definiram essas novas perspectivas de ciência como paradigmas de pesquisa, a partir da análise das questões ontológicas, epistemológicas e metodológicas que orientam os pesquisadores. Nesse sentido, a opção de se utilizar os estudos de Guba e Lincoln (1994) como base teórica da presente pesquisa adveio, justamente, da importância em desvendar quais as concepções axiológicas que orientam, atualmente, as pesquisas na área da Educação.

Em sendo assim, o presente artigo, resultado de estudos realizados na disciplina Seminário de Prática de Pesquisa I, pertencente ao Programa de Pós-Graduação Stricto Sensu em Educação da Universidade Estadual do Ceará (UECE), teve como objetivo principal analisar a presença dos paradigmas de pesquisa nas teses de doutorado do Programa de Pós-Graduação Stricto Sensu em Educação da UNISINOS, no período compreendido entre 2013 a 2018.

$\mathrm{O}$ artigo, pois, foi estruturado em três partes. A primeira buscou definir o que se entende como paradigma de pesquisa, a partir de diferentes concepções de alguns dos mais importantes teóricos que tratam da temática. A segunda parte apresentou a concepção de paradigmas na perspectiva de Guba e Lincoln (1994). Por fim, a terceira parte concentrou-se na identificação e análise dos paradigmas que nortearam as teses de doutorado do Programa de Pós-Graduação Stricto Sensu em Educação da UNISINOS.

Acredita-se que todas essas discussões acerca do assunto parecem apontar para uma premissa básica, qual seja a busca pela compreensão de paradigmas em pesquisa educacional é premente e precisa ser mais difundida na comunidade acadêmica que estuda e produz pesquisa sobre o tema. Talvez, somente assim, os critérios rigor e cientificidade, enfim, libertem-se dos parâmetros positivistas.

\section{Metodologia}

No que diz respeito à metodologia utilizada no estudo, foi realizada uma pesquisa do tipo exploratória e descritiva, pois teve o propósito de proporcionar uma maior familiaridade com o problema, além de descrever o fenômeno (Gil, 2019), de natureza mista (Creswell \& Clark, 2013), uma vez que foi utilizado tanto o método quantitativo, no momento de mapear a 
quantidade de teses defendidas pelos estudantes do Programa de Pós-graduação Stricto Sensu em Educação da Unisinos no período mencionado, quanto o método qualitativo, presente na análise dos paradigmas presentes nas teses.

Inicialmente, é importante explicar, mesmo que de forma breve, os critérios utilizados para a investigação dos paradigmas encontrados nas teses de doutorado do Programa de Pós-Graduação em Educação da UNISINOS, produzidas no período de 2013 a 2018. A pesquisa foi realizada na plataforma Sucupira, base de referência do Sistema Nacional de PósGraduação (SNPG) (Brasil, 2019). Nessa plataforma, embora o número de busca constasse de 105 (cento e cinco) teses, duas delas apareceram em duplicidade e numa delas não foi possível fazer o download. Em sendo assim, nessa plataforma, foram extraídas e analisadas partes das 103 (cento e três) teses de doutorado em educação da UNISINOS.

Para tanto, de cada tese do referido período, foram realizadas leituras, tanto da seção do Resumo, como dos elementos metodológicos localizados na introdução do trabalho ou do capítulo destinado a Metodologia (quando havia), cuja intenção era encontrar elementos de diferenciação. Desta forma, delimitou-se os campos dos relatórios de pesquisa que seriam analisadas, já que não era possível, no tempo estabelecido para o desenvolvimento deste trabalho, a leitura de "capa a capa" de cada tese de doutorado. Assim, o capítulo da metodologia (ou equivalente) foi, por certo, considerado o elemento decisivo para estabelecer a diferenciação entre os elementos dos paradigmas encontrados.

O que logo se percebeu, após o levantamento dos dados, é que nenhum dos quatro paradigmas (positivista, póspositivista, teoria crítica e construtivismo), estabelecidos por Guba e Lincoln (1994), se apresentou de forma pura, isolada. Há, pode-se dizer, na totalidade ( $\mathrm{n}=100 \%$ ) das teses de doutorado da UNISINOS (2013-2018), uma mescla de, pelo menos, dois paradigmas. Isto ocorre por um motivo bastante interessante. Os paradigmas possuem, em certa medida, uma generalização dos próprios autores, Guba e Lincoln (1994), ao defini-los, o que significa dizer, em consequência, que são abstrações realizadas por sujeitos no sentido de generalizar uma dada corrente filosófica, uma determinada escola teórica ou mesmo uma tendência cognitiva de pensamento científico. Esta abstração, por oportuno, ocorre por vias epistemológicas, como também pelo estabelecimento de critérios, mencionados em tabelas elaboradas pelos autores, com as definições das categorias que eles consideraram necessárias para a justa delimitação desses paradigmas mencionados anteriormente.

Estas categorias foram escolhidas por um simples motivo, qual seja a necessidade de se definir os limites de cada paradigma. Ocorre que a ciência trabalha com generalizações, e no caso das generalizações definidas por Guba e Lincoln (1994), este procedimento deve ser feito por uma abstração filosófica em que são elencados critérios e categorias que possam mensurar a existência, separação ou definição de um dado paradigma de pesquisa científica.

Desta forma, como já mencionado no início desta seção, o fato de não ter encontrado, de forma pura e isolada um paradigma, não significa dizer, obviamente, que não é possível encontrá-lo ou mesmo postular sua inexistência em pesquisas científicas. E embora tenha-se constatado a presença de mais de um paradigma em cada tese de doutorado da UNISINOS (20132018), também não se pode afirmar, das seções que foram lidas, qual dos paradigmas tiveram a maior ou menor incidência. Ou seja, mesmo na identificação de mais de um paradigma, não foi possível definir qual deles ocorreu de forma mais ou menos intensa numa determinada pesquisa e a razão já foi explicada (o tempo para a produção do presente artigo científico).

Além disso, também se averiguou que mesmo o pesquisador elegendo um paradigma de forma contundente, foram constatados elementos pertencentes a outros paradigmas, donde se pode afirmar que, de fato, não há a presença de um paradigma de forma pura. A questão é que a observância da presença de mais de um paradigma em cada uma das teses, foi de fundamental importância para o desenvolvimento da análise a seguir exposta.

Essa maleabilidade epistemológica, provavelmente, ocorreu pela própria constituição da pesquisa científica do programa da UNISINOS, como pela escolha metodológica e teórica realizada nas teses. A contribuição de vários autores, alguns até com posições definitivamente divergentes a respeito do tema, torna o trabalho mais rico epistemologicamente, porém, agrega 
diversos elementos que, por vezes, turvam a delimitação de um dado paradigma devido aos muitos elementos teóricos ali encontrados.

Assim sendo, a análise destes paradigmas apenas foi possível pelo estabelecimento de critérios antepostos que permitiram delimitar, minimamente, onde um e outro começa, ou, em alguns casos, quais elementos que uma determinada tese possuía de um ou outro paradigma. Afinal, como já discorrido, pode-se definir os paradigmas por diversas categorias epistemológicas, ontológicas e metodológicas. No entanto, é no componente metodológico que eles tendem a não se repetirem, ou que pelo menos seus elementos de diferenciação se tornam mais claros, mais evidentes, menos passíveis de relativismos subjetivos.

Desse modo, observou-se a ocorrência dos paradigmas e não a existência pura e isolada deles nos trabalhos de modo que se estabeleceu uma separação epistemológica entre macro-Paradigma e micro-Paradigma para contemplar os diversos elementos outros teóricos postos nas teses que dizem respeito a expressão do arcabouço epistemológico da pesquisa. O macroParadigma, assim, diz respeito a um dos quatro paradigmas elencados por Guba e Lincoln (1994), a saber, positivista, póspositivista, teórica crítica e construtivismo. O micro-Paradigma, por sua vez, remete-se aos diversos elementos epistemológicos que norteiam a pesquisa em questão. Portanto, podem ser derivados do arcabouço teórico do autor utilizado para fundamentar a tese ou do consenso intersubjetivo posto pelo conjunto de autores utilizados no trabalho, por exemplo, pesquisa ação, pesquisa participante, governamentabilidade, método analítico, história oral etc.

Não se teve aqui a menor pretensão de enquadrar um dado paradigma numa determinada tese de forma isolada, na medida em que os próprios autores Guba e Lincoln (1994) lançam mão de um variado arcabouço epistemológico para darem respaldo aos seus complexos objetos de pesquisas, o que é, particularmente, bastante desejável que isto ocorra em uma pesquisa científica. Esta variabilidade epistemológica confere aos trabalhos uma certa maleabilidade teórica que agrega diversos elementos de outros paradigmas em um ou outro momento da pesquisa.

Torna-se bastante complexo, no entanto, postular que uma pesquisa se orienta a partir de apenas um paradigma por um motivo bem simples: as teses recebem contribuições de elementos de outros paradigmas em dados momentos, o que não quer dizer, necessariamente, que estes elementos ocorrem em todos os trabalhos ou na totalidade do trabalho, mas sim que estão presentes e, de alguma forma, influenciam a busca teórica de explicação do objeto.

Nesse sentido, elegeu-se neste trabalho, para a análise dos dados, o parâmetro do macro-Paradigma como expressão de uma abstração necessária para expressar a ocorrência de elementos epistemológicos que configuram a presença de um dado paradigma. No mesmo processo de pensamento, o micro-Paradigma também significa a ocorrência de elementos epistemológicos. Contudo, eles dizem respeito a identificação teórica dos autores ou do conjunto de autores contida na pesquisa; são, pois, elementos menores em relação ao macro-Paradigma e são derivados da corrente filosófica de um dado autor e, que, não, obrigatoriamente, expressa o paradigma maior contido na tese.

Este foi, enfim, o procedimento metodológico utilizado para tentar identificar os paradigmas e, ao mesmo tempo, contemplar os outros diversos elementos epistemológicos que compõem as pesquisas nas teses de Doutorado do Programa de Pós-Graduação em Educação da UNISINOS (2013-2018).

\section{Paradigmas de Pesquisa: Conceito, Características, Contradições e Confluências}

\subsection{O que é um paradigma de pesquisa?}

Antes de adentrar no objetivo específico do presente artigo, qual seja analisar quais os paradigmas que orientaram as pesquisas realizadas na pós-graduação stricto sensu em Educação da UNISINOS, convém pontuar o que, efetivamente, se compreende como paradigma. Trata-se de um esclarecimento importante em razão das diferentes acepções que essa terminologia apresenta no campo da ciência. O termo paradigma, primeiramente, é multidisciplinar, já que não é usado de maneira engessada. 
Seu conceito, inclusive, trouxe tantas reflexões que ele não é mais um termo exclusivo da seara científica, pois é frequentemente empregado em discursos que engendram a construção do pensamento crítico, social, cultural e político.

Do ponto de vista científico, os paradigmas são comumente entendidos como um conjunto de crenças básicas, ou concepções de mundo que orientam a atuação dos pesquisadores. Um dos primeiros autores a tratar sobre o assunto, a partir dessa perspectiva, foi Thomas Khun, na obra "A estrutura das revoluções científicas", no início da década de 60. Em sua concepção, os paradigmas são esquemas conceituais, teóricos, metodológicos e instrumentais criados e compartilhados pelos seres humanos, a partir dos quais são construídos modelos para orientar a atuação da comunidade científica (Khun, 1970).

Em sua obra, Khun descreve as quatro (4) fases da Revolução das Ciências nas quais observou que existia uma fase préparadigmática onde não há consenso entre pesquisadores das ciências e que nesta fase um paradigma irá ser o vencedor para que ocorra a fase seguinte, a da estabilidade das ciências normais. Durante essa fase das ciências normais, há produção científica, estabilidade e confiabilidade acadêmica até que ocorra uma nova fase, qual seja a crise científica. Nessa fase, um novo paradigma rompe com o anterior ou abandona totalmente, podendo causar uma Revolução Científica (que seria uma quarta fase ou exceção para Khun).

Seguindo concepção semelhante, Guba e Lincoln (1994), autores cujas teorias guiaram essa pesquisa, compreendem os paradigmas como crenças básicas que orientam as ações dos investigadores, a partir de aspectos ontológicos, epistemológicos e metodológicos. Da mesma forma, embora utilizando uma nomenclatura diferente, Creswell (2010) entende os paradigmas como "concepções filosóficas" que traduzem as ideias e crenças de mundo que guiam as práticas dos pesquisadores. Além disso, ele destaca diferentes terminologias utilizadas por outros autores, como: "epistemologias e ontologias (Crotty, 1998) ou metodologias de pesquisa amplamente concebidas (Neuman, 2000)" (Creswell, 2010, p. 28). Tratam-se, basicamente, de orientações gerais sobre o mundo e sobre a natureza da pesquisa que conduzem o trabalho do pesquisador.

\subsection{Aspectos ontológicos, epistemológicos e metodológicos que envolvem os paradigmas de pesquisa}

Conforme explicitado no tópico acima, os paradigmas servem para embasar as ideias e tomadas de decisões do pesquisador. No entanto, comumente, não estão explícitos nos textos científicos, teses, dissertações ou artigos as concepções filosóficas que influenciam as escolhas do pesquisador. Da mesma forma, a abordagem, o tipo e método de pesquisa que não deveriam, segundo Creswell (2010), ser olvidadas na escrita dos trabalhos. Pelo contrário, para ele, deveria haver uma seção exclusiva para explanar melhor as opções paradigmáticas do pesquisador, se pós-positivista, construtivista, reivindicatória, participativa ou pragmática, por exemplo. O referido autor defende, ainda, que a seção deveria incluir "uma definição das considerações básicas dessa concepção, como a concepção moldou sua abordagem de pesquisa [...]" (Creswell, 2010, p. 28).

Nota-se, portanto, que o tripé, concepções filosóficas ou pressupostos filosóficos (pós-positivista, construtivista, participativa, pragmática), métodos de pesquisas (pesquisa qualitativa ou quantitativa ou pesquisa mista, tipo experimental, etnográfica etc.), estratégias de investigação está intrinsicamente ligado e entrosado como numa engrenagem (Creswell, 2010, p. 28).

No plano dos pressupostos filosóficos trazidos por Creswell (2010), é ilustrado como são os níveis de reflexão filosóficos, como estes orientam a visão da realidade e quais as suas implicações na prática. $\mathrm{O}$ autor, por exemplo, alude à ontologia como o pressuposto ou concepção que indaga o que é a natureza da realidade.

O pressuposto axiológico, por sua vez, relaciona-se com os valores a partir dos quais os cientistas embasam as pesquisas e qual o seu papel no desenvolvimento e resultado da investigação. $\mathrm{O}$ aspecto epistemológico diz respeito ao conhecimento e a forma como é construído e propagado, bem como a relação entre o pesquisador e o objeto de pesquisa.

Por último, mas não menos importante, é mister destacar o modus operandi ou os métodos utilizados pelo pesquisador para alcançar os objetivos da pesquisa (Creswell, 2018). 
A seguir, apresenta-se a Figura 1 com um demonstrativo das questões que influenciam a natureza dos paradigmas na perspectiva de Creswell (2018):

Figura 1 (F1): A natureza dos paradigmas na perspectiva de Creswell (2018).

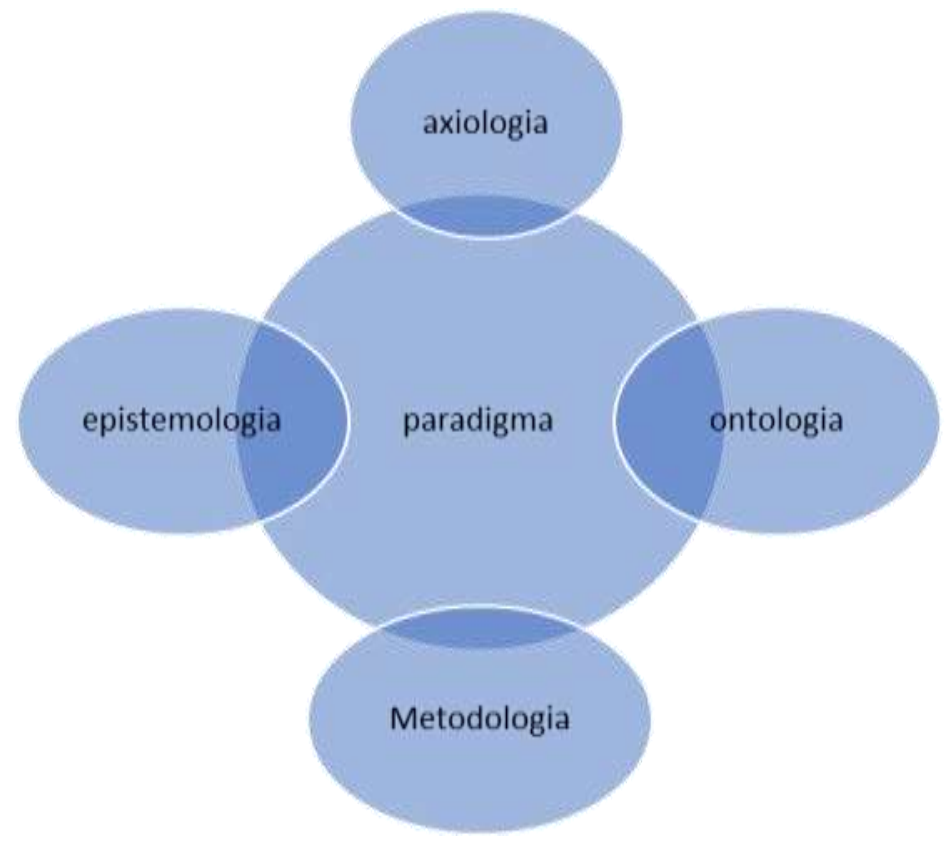

Fonte: Autoras (2019).

A figura acima, elaborado para ilustrar a presente pesquisa a partir das ideias de Creswell (2018), demonstra que a axiologia (valores), a epistemologia (conhecimento) e a ontologia (essência) contemplam um sistema de crenças que orientam a criação de paradigmas de pesquisa erigidos como verdadeiras premissas responsáveis por direcionar as investigações. O método ou metodologia, por sua vez, será o modus operandi da pesquisa ou aplicação de toda essa engrenagem de ideias de maneira sistematizada, organizada e com objetivo definido.

Assim como Creswell (2018), Guba e Lincoln (1994), também levaram em consideração os aspectos ontológicos, metodológicos, epistemológicos e axiológicos para determinar os tipos de paradigmas de pesquisa que orientarão a atuação do pesquisador, razão pela qual foram escolhidos para embasar a presente pesquisa.

Importante salientar, contudo, que esses autores entendem que a mescla de diferentes paradigmas de pesquisa precisa atender a certos critérios e que existem paradigmas inconciliáveis em razão de sua incompatibilidade axiológica. Nessa perspectiva, o paradigma pós-positivista seria inconciliável com a teoria crítica e com o construtivismo, por exemplo.

Acredita-se que, por essa razão, o Pragmatismo, tipo de paradigma apontado por autores como Creswell (2018) e Sampiere, Colado e Lucio (2013), que se caracteriza pela diversidade e ecletismo de enfoques, ideias e métodos de pesquisa, não foi adotado por Guba e Lincoln (1994).

A partir dos resultados da presente pesquisa é possível aferir, ao menos preliminarmente, se os critérios axiológicos de comensurabilidade adotados por esses autores estão sendo levados em consideração pelos pesquisadores da área da Educação.

\subsection{Os paradigmas de pesquisa conforme Egon G. Guba e Yvonna S. Lincoln}

\subsubsection{Os paradigmas e as crenças: reflexões iniciais}

Os paradigmas de pesquisa, de acordo com Guba e Lincoln (1994), são sistemas básicos de crenças, ou visões de mundo que orientam o trabalho do pesquisador. Ou seja, um paradigma, conforme Santos (2002), é “um conjunto de crenças 
básicas que tratam de princípios elementares ou do foro mais profundo. Representa a visão de mundo que cada um tem, da sua natureza e do lugar que cada sujeito ocupa nesse mundo". Já as crenças, "dizem respeito a um conjunto de pressupostos básicos sobre a natureza das coisas que enformam (sic) o nosso pensamento e que admitimos como verdadeiros" (idem). Ou seja, para o autor, por mais que as crenças possam ser mais ou menos justificadas, não há como refutar ou mesmo comprovar a sua veracidade.

A partir dessa perspectiva, Guba e Lincoln (1994) dividem os paradigmas tomando por base critérios ontológicos, epistemológicos, metodológicos. Entretanto, "embora constituindo três campos de análise distintos, eles são interrelacionados (sic), isto é, são interdependentes. Por outras palavras, "a forma como nos posicionamos face a um grupo de questões de um dos campos de análise influencia e determina a resposta a dar às questões de outro campo" (Santos, 2002).

A questão ontológica, para Guba e Lincoln (1994), corresponde à forma e à natureza da realidade e o que, de fato, é possível conhecer sobre ela. Se, por exemplo, o pesquisador entender que a realidade é pressuposta, irá buscar a existência material do fenômeno pesquisado, de maneira que apenas as questões que possibilitarão alcançar essa materialidade importam. Outras questões, como aquelas ligadas a valores, serão deixadas de lado para não prejudicar a objetividade dos resultados. A questão epistemológica, por sua vez, diz respeito a natureza daquilo que é conhecido, o que deveria ser conhecido e o que, de fato, pode ser conhecido. Assim, se o pesquisador entender que a realidade é pressuposta, sua postura será objetiva, no sentido de buscar conhecer essa realidade, desconsiderando outras questões que possam prejudicar, de alguma forma, essa objetividade. Já as questões metodológicas relacionam-se com a forma de como o pesquisador irá proceder para alcançar os resultados almejados. Nessa perspectiva, a pesquisa que busca descobrir a realidade pressuposta, por exemplo, demandará controle dos possíveis fatores externos que possam interferir na objetividade e rigor da investigação. Ou seja, as questões metodológicas, para os autores, muito mais do que especificamente discutir os métodos, devem refletir sobre o modo de proceder do investigador de forma a alcançar os conhecimentos que acredita serem possíveis conseguir (Santos, 2002).

Além desses três critérios, Guba e Lincoln (1994) também os relacionam a algumas questões práticas, como: a finalidade da investigação, a natureza do conhecimento, a forma como o conhecimento se acumula, os critérios para definir a qualidade ou o rigor da pesquisa, o papel dos valores na investigação, o lugar da ética na investigação, a postura do investigador com relação ao resultado da pesquisa, como se dá o treinamento de pesquisadores iniciantes e a questão da possibilidade ou não da comensurabilidade entre os paradigmas de pesquisa, critério também analisado nesse artigo, já que, os autores Guba e Lincoln (1994), destacam que misturar elementos de um paradigma dentro de outro somente é aceitável quando obedecidos critérios mínimos de convergência axiológica. Para eles, alguns paradigmas são tão diferentes uns dos outros que podem, até mesmo, se comportar como adversários, sendo, portanto, inconciliáveis.

Assim, Egon et al. (1994), a partir da análise das questões ontológicas, epistemológicas e metodológicas acima discorridas, definiram as diversas concepções de pesquisa em paradigmas. Em 1994, os autores estabeleceram quatro paradigmas, quais sejam: o Positivismo e o Pós-Positivismo, conhecidos como Paradigmas Clássicos, e a Teoria Crítica e o Construtivismo, conhecidos como Paradigmas Alternativos. E, embora em 2005, Egon et al. tenham apresentado o paradigma Participativo, eles mesmos ressaltaram que esse paradigma nada mais é do que uma variação mais detalhada do paradigma construtivista. Ou seja, para eles, o paradigma participativo “(..) é um excelente exemplo do detalhamento hermenêutico tão presente em nosso próprio ponto de vista, o construtivismo" (Guba \& Lincoln, 2005, p. 170). Por esse motivo, optou-se, nesse trabalho, por preservar a concepção inicial dos autores (1994) apenas com os quatro paradigmas acima mencionados.

Feitas essas considerações iniciais, analisa-se, individualmente, os paradigmas de pesquisa, conforme a perspectiva dos autores Egon et al. (1994), destacando que não há supremacia de qualquer paradigma em relação a outros, uma vez que todos são construções humanas que servem para nortear a identidade dos pesquisadores, bem como os limites daquilo que é permitido dentro de uma pesquisa legítima. 


\subsubsection{O positivismo}

Conforme sustentam Guba e Lincoln (1994), o paradigma positivista é o que tem prevalecido há, pelo menos 400 anos, tanto nas pesquisas referentes às chamadas ciências "duras" que exigem resultados objetivos e quantificáveis, tais como a matemática, a física e a química, como também nas pesquisas humanas e sociais, já que os pesquisadores adotam, predominantemente, esse paradigma acreditando que, dessa forma, atribuirão mais cientificidade e rigor aos seus achados.

No que tange à ontologia, esse paradigma traz o conceito de verdade como um elemento imutável e passível de uma completa apreensão pelo pesquisador que assume, perante a pesquisa, uma postura generalista e reducionista. Do ponto de vista epistemológico, busca-se preservar a objetividade, razão pela qual, deve ser eliminado qualquer fator que possa relativizar os resultados da pesquisa. O objeto, pois, deve ser analisado de forma imparcial, não devendo o pesquisador influenciá-lo ou mesmo ser influenciado por ele. Por esse motivo, a metodologia empregada deve ser cuidadosamente controlada para evitar a "contaminação" dos dados por fatores que possam interferir na objetividade dos resultados. As hipóteses são, portanto, elaboradas propositalmente para serem sujeitas a verificações empíricas.

Com relação ao objetivo da investigação, os adeptos desse paradigma buscam explicações para os fenômenos. Desse modo, o intuito é que a capacidade de prever e controlar os resultados se aperfeiçoe ao ponto de alcançar a verdade, que poderá ser generalizada para todos os casos semelhantes. A produção do conhecimento, assim, ocorre quando é possível verificar hipóteses que, caso confirmadas, devem ser aceitas como verdades absolutas. Esse conhecimento vai sendo acumulado e servindo de base para a produção de outros conhecimentos. A qualidade da investigação, pois, é alcançada quando há objetividade (o pesquisador assume uma postura neutra diante dos fenômenos) e os resultados podem ser generalizados, o que caracteriza o rigor para os adeptos desse paradigma de pesquisa.

Importante ressaltar, ainda, que os valores estão excluídos da investigação para os adeptos do paradigma positivista, de maneira que se faz necessário respeitar a neutralidade como forma de preservar o rigor. Os valores, dessa forma, são interpretados como elementos de confusão que prejudicam a objetividade da pesquisa e que, por isso, devem ser desconsiderados. $\mathrm{O}$ investigador age, diante desse cenário, como um cientista desinteressado, buscando apenas informar os resultados aos responsáveis por formular políticas, ações e propostas de mudanças.

A ética, para os positivistas, é considerada de grande importância, mas é encarada como um elemento extrínseco ao processo investigativo. O comportamento ético do pesquisador, dentro dessa perspectiva, é policiado por mecanismos externos de controle como códigos profissionais de conduta e comitês de seres humanos. No que se refere ao treinamento dado aos pesquisadores iniciantes, os adeptos do paradigma positivista concentram-se em enfatizar os conhecimentos técnicos, em especial os métodos quantitativos.

Do ponto de vista axiológico, a finalidade dos positivistas é o saber proposicional a respeito do mundo. No que se refere à comensurabilidade, ou seja, a possibilidade de mesclar paradigmas, na visão de Guba e Lincoln (1994), é possível misturar apenas paradigmas de matriz positivista e pós-positivista. E com relação ao controle, os positivistas assumem totalmente a direção do estudo, desde a formulação dos problemas até a coleta de dados, as representações dos participantes e a forma de publicidade dos achados. Tudo isso, com o intuito de tornar a pesquisa o mais objetiva e rigorosa possível.

\subsubsection{O pós-positivismo}

Os adeptos do paradigma pós-positivista, no que se refere à ontologia, também defendem que a realidade é pressuposta. Contudo, assumem que a verdade pode ser apenas parcialmente apreendida, em razão das limitações inerentes aos seres humanos e à natureza dos fenômenos. Adota-se, assim, um realismo crítico em que o pesquisador busca se aproximar, na maior medida possível, da verdade, sabendo, entretanto, que é impossível apreendê-la em sua totalidade. Nas palavras de Guba e Lincoln (1994, p. 110): 
Reality is assumed to exist but to be only imperfectly Apprehendable because of basically flawed human intelectual mechanisms and the fundamentally intractable nature of phenomena. The ontology is labeled as critical realism (Cook \& Campbell, 1979) because of the posture of proponentes that claims about reality must be subjected to the widest possible critical examination to facilitate apprehending reality as closely as possible (but never perfectly).

Com relação à epistemologia, afasta-se o dualismo próprio da perspectiva positivista, já que se assume a limitação do pesquisador para apreender completamente a realidade, contudo, ainda se mantém a objetividade, eleita como um critério essencial para resguardar a cientificidade das pesquisas. A metodologia utilizada, nesse sentido, é experimental manipulativa modificada, mediada por uma multiplicidade crítica. É, pois, admitida a utilização de métodos qualitativos.

No que se refere ao objetivo da investigação, assim como os adeptos do positivismo, os pós-positivistas também buscam explicações para os fenômenos prevendo e controlando os resultados, mas admitem que a verdade não é completamente passível de ser apreendida, em razão da falibilidade humana. Dessa maneira, o conhecimento produzido é considerado como um fato provável. O acúmulo desse conhecimento servirá de alicerce para a produção de outros conhecimentos também considerados como possivelmente verdadeiros.

O rigor da investigação, assim como para os adeptos do paradigma positivista, é alcançado por meio da objetividade do pesquisador que deve assumir uma postura neutra diante do objeto. Os resultados também devem ser passíveis de generalização, embora se admita que os achados são provavelmente verdadeiros.

Com relação ao papel dos valores para o resultado das pesquisas, na mesma perspectiva dos positivistas, os adeptos do pós-positivismo entendem que a objetividade deve ser preservada em nome do rigor da pesquisa, razão pela qual as questões valorativas devem ser desconsideradas para não prejudicar a confiabilidade e possibilidade de generalização dos resultados. $\mathrm{O}$ investigador assume uma postura neutra, apenas divulgando os resultados, sem se responsabilizar por concretizar possíveis transformações. Do ponto de vista ético, os pós-positivistas, à semelhança dos positivistas, adotam mecanismos externos de controle como comitês de seres humanos e códigos profissionais de conduta.

No que tange ao treinamento de pesquisadores iniciantes, os pós-positivistas valorizam os métodos quantitativos, aliados a métodos qualitativos, com o intuito de minimizar as críticas a respeito da pretensa infalibilidade dos resultados defendida por seus antecessores positivistas. Com relação à comensurabilidade, conforme Guba e Lincoln (1994), como já mencionado, é perfeitamente possível mesclar paradigmas positivistas e pós-positivistas. Com relação ao controle do estudo, do mesmo modo como os positivistas, os pós-positivistas concentram toda a direção da pesquisa, como forma de preservar a objetividade e o rigor.

\subsubsection{A Teoria Crítica e posições ideológicas relacionadas}

A Teoria Crítica, na concepção de Guba e Lincoln (1994) abrange uma série de paradigmas alternativos, tais como: neomarxismo, feminismo, materialismo, pesquisa participante etc. Os defensores desse paradigma entendem que, do ponto de vista ontológico, o conceito de verdade foi, paulatinamente, sendo moldado por fatores sociais, culturais, econômicos, éticos e de gênero. Grupos que detinham o poder foram responsáveis por criar uma realidade que, atualmente, está cristalizada. Trata-se, portanto, de uma realidade fictícia, fabricada ao longo da história, que os pesquisadores críticos buscam desconstruir.

A epistemologia adotada é transacional e subjetiva, de modo que o investigador compreende e assume que sua subjetividade, assim como a subjetividade dos investigados, naturalmente, influencia o resultado da pesquisa que é mediada por valores e se desenvolve a partir da interação do pesquisador com o objeto ou grupo. A metodologia empregada é dialética, pois visa, a partir do diálogo com os sujeitos da investigação, descobrir os saberes históricos encobertos pelos poderes dominantes, com o intuito de transformar a realidade. 
O objetivo dos adeptos desse paradigma de pesquisa é a transformação e a emancipação dos sujeitos. Os investigadores compreendem que a verdade que foi contada pelos detentores do poder precisa ser reescrita pelos próprios excluídos. O conhecimento, sob essa percepção, ocorre quando antigas "verdades" cedem lugar a novas versões contadas a partir da perspectiva dos desfavorecidos. Para defensores desse paradigma de pesquisa, pois, o conhecimento não se acumula, ele se transforma e cresce a partir de novas perspectivas sociais, culturais, políticas, econômicas, étnicas e de gênero, que recontam a história a partir de um processo dialético. Por esse motivo, a qualidade da pesquisa é caracterizada pela contextualização histórica da investigação que proporcionará o estímulo à ação, à emancipação dos sujeitos e à transformação da estrutura existente.

Para os estudiosos da Teoria Crítica e posições ideológicas relacionadas, assim, os valores têm lugar de destaque, uma vez que pautam toda a investigação. Inverte-se a lógica valorativa historicamente construída para dar lugar a novos valores que possibilitarão uma nova apreciação da realidade. O investigador assume o caráter de um intelectual transformador que tem, como principal papel, afastar a ignorância e romper com a realidade contada e manipulada historicamente. A ética, para eles, é intrínseca, na medida em que o investigador apresenta uma postura de revelador da realidade escondida, buscando minar a ignorância e os mal-entendidos reproduzidos historicamente.

No que tange ao treinamento dos pesquisadores iniciantes, os adeptos da Teoria Crítica devem conhecer as diferenças entre os paradigmas de pesquisa e dominar os métodos quantitativos e qualitativos para que, dessa forma, sejam capazes de exercer seu papel de investigadores dialógicos/dialéticos. Além disso, devem ser auxiliados a compreender os contextos histórico, social, político, cultural, econômico, étnico e de gênero que influenciam o que é retratado como verdade.

Com relação à comensurabilidade, Guba e Lincoln (1994) destacam que esse paradigma não pode ser mesclado com paradigmas de matriz positivista e pós-positivista, em razão de sua incompatibilidade axiológica, mas pode apresentar uma comensurabilidade com o paradigma construtivista. Por fim, com relação ao controle do estudo, os defensores da Teoria Crítica e posições ideológicas relacionadas acreditam que os participantes, mais especificamente os excluídos historicamente, devem, cada vez mais, assumir o controle da pesquisa para que, em consequência, seja possível desvelar a realidade por trás das estruturas de poder, em busca da justiça social.

\subsubsection{O Construtivismo}

O construtivismo é também definido por Guba e Lincoln (1994) como um paradigma alternativo, que se fundamenta no relativismo ontológico. De acordo com essa concepção, as realidades são criadas a partir de múltiplas apreensões mentais que podem ser individuais ou coletivas. Essas realidades são construídas a partir de experiências locais e sociais, por essa razão são mutáveis.

Do ponto de vista epistemológico, a pesquisa amparada por esse paradigma é transacional e subjetiva, pois o investigador e o objeto de pesquisa estão ligados de forma interativa. A metodologia é dialética e hermenêutica, uma vez que os resultados são construídos a partir da interpretação que se faz da relação dialógica entre o pesquisador, o objeto de pesquisa, o meio e as interações sociais.

Os construtivistas têm como objetivo reconstruir a realidade, com base em novas perspectivas, em busca de um consenso, mas sempre abertos a novas interpretações da realidade. $O$ investigador assume um papel de participante e facilitador, postura criticada principalmente pelos positivistas e pós-positivistas que acreditam que isso compromete a objetividade e a imparcialidade que deve permear a pesquisa.

O conhecimento, portanto, se constrói a partir da convergência alcançada por meio de múltiplas visões acerca de um fenômeno. Essas construções estão sujeitas a contínuas revisões e mudanças em razão da dialética que é uma característica 
marcante desse tipo de postura investigativa. O acúmulo do conhecimento é relativo, já que é mutável e se reconstrói continuamente por meio de um processo hermenêutico/dialético.

No que se refere ao rigor, ou seja, aos critérios utilizados para demonstrar a qualidade da pesquisa, Guba e Lincoln (1994) apontam que os construtivistas se baseiam na confiabilidade, credibilidade e autenticidade. Em seu entendimento, apesar da boa receptividade desses critérios, a questão do rigor ainda não é bem definida entre os defensores desse paradigma de pesquisa.

Os valores, para os construtivistas, assim como para os adeptos da Teoria Crítica e posições ideológicas relacionadas, têm um importante papel na investigação, uma vez que são levados em conta para a interpretação e construção individual ou coletiva da realidade. A ética, para os adeptos desse paradigma de pesquisa é intrínseca, na medida em que os valores dos participantes são incluídos nos resultados da pesquisa, em uma relação de hermenêutica/dialética.

Com relação ao treinamento dos pesquisadores iniciantes, assim como os adeptos da teoria crítica, os construtivistas devem conhecer os métodos quantitativos e qualitativos com o intuito de bem desempenharem sua função investigativa hermenêutica/dialética. Importante, também, que sejam auxiliados a compreender o contexto para que possa estimular os participantes a construírem conhecimentos, exercendo a função de facilitador/participante.

No que diz respeito à comensurabilidade, os autores entendem que é possível mesclar o construtivismo e a teoria crítica, em razão de uma base axiológica compatível, o que não ocorre com relação aos paradigmas positivista e pós-positivista.

Quanto ao controle do estudo, os construtivistas, assim como os adeptos da teoria crítica, defendem que é necessário, cada vez mais, dar poder aos participantes da pesquisa, para que possam efetivamente mostrar os problemas e propor as saídas para que os resultados sejam compartilhados com um número, cada vez maior, de pessoas fora da comunidade, promovendo, então, a emancipação humana.

Os paradigmas de pesquisa na visão de Guba e Lincoln (1994), enfim, servem como uma "bússola" que guia o pesquisador durante a trajetória da investigação. Traduzem suas principais concepções, suas crenças básicas acerca do que é a realidade, em que medida esta pode ser apreendida e de que maneira. São esses paradigmas que, para eles, devem pautar as atitudes do pesquisador e que determinam os procedimentos que caracterizam o rigor, a qualidade e a cientificidade da pesquisa.

Nessa perspectiva, a comunicação entre os diversos paradigmas, buscando o melhor que cada um tem a oferecer, deve ser vista com cautela, uma vez que unir paradigmas axiologicamente inconciliáveis como, por exemplo, os de matriz positivista e pós-positivista com a teoria crítica ou o construtivismo, podem, na concepção dos autores, comprometer o rigor da pesquisa.

\section{Resultados e Discussão}

Como já afirmado acima, da leitura dos resumos e do capítulo da metodologia (ou equivalente) das teses de doutorado em educação da UNISINOS (2013-2018), a primeira assertiva que se apresenta é que há, sim, uma mescla de, pelo menos, dois paradigmas em todas elas. Reforça-se, mais uma vez, que, em razão do prazo estabelecido para a entrega deste artigo, não foi possível a leitura de todas as teses de "capa a capa", de modo que o foi verificado é a inexistência de apenas um paradigma nos relatórios de pesquisa. Ao contrário, percebeu-se que os pesquisadores se apoiam numa multiplicidade de paradigmas para o desenvolvimento de suas pesquisas.

Esse cenário reflete uma reflexão importante em relação ao paradigma com o objeto de pesquisa, já que eles (os objetos) não falam por si. Todos os sujeitos são intérpretes, de um jeito ou de outro. Uns mais e outros menos. E se se considerar que, independentemente do método, estar-se à procura do conhecimento humano, realmente, não faz muito sentido apoiar-se em somente num paradigma ou noutro. Santos (2002, p.160), apropriadamente, faz alguns questionamentos instigantes a respeito: 
Se tomarmos por base este modelo que estabelece diversas distinções entre paradigmas, é possível repensar a relação entre a abordagem de investigação escolhida num dado estudo e aquilo que ele pretende estudar. Diversos autores (por ex. Patton, 1980; Reichardt e Cook (1979) defendem que a escolha do paradigma de investigação é determinada pelas características do objecto de estudo. Questionamos, contudo, até que ponto tal é de facto verdade. A relação causaefeito parece-nos, no mínimo, questionável. Até que ponto o próprio problema do estudo não é já ele determinado pelo paradigma do investigador? É o paradigma que modela o problema ou é o problema que modela o paradigma? Como questionam Strauss e Corbin (1990), como se explica que investigadores que têm um dado paradigma são sempre levados a formular questões de um certo tipo? Até que ponto as crenças do investigador não modelam desde logo as questões que para si são relevantes e dignas de estudo?

Assiste, pois, razão a Santos (2002) quando defende que importante não é, necessariamente, saber quem vem antes, o paradigma ou o problema, mas, sim, encontrar uma forte consistência entre eles. Afinal, é perfeitamente possível identificar na literatura diversos métodos que se enquadram num mesmo paradigma. A questão é que "perspectivas unilaterais sobre o mundo não são capazes de explicar a relação complexa entre realidade material e perspectiva humana" (Kincheloe, 2007, p. 39).

É inegável que os paradigmas clássicos de pesquisa são referências históricas, mas, ao mesmo tempo, também são monorracionais, monorreferenciais; razão pela qual a mudança necessária é a passagem para a complexidade, bem como para a multirreferencialidade (Borba, 2001). A interdisciplinaridade é, sem dúvida, “(...) uma atitude aberta, simpática às diversas ciências, às diversas disciplinas, isto é, de sermos curiosos acerca do fenômeno complexo que é viver e refletir sobre a vida. (Borba, 2001, p. 126).

\subsection{A mescla de paradigmas e a teoria de Guba e Lincoln (1994)}

Percebeu-se, claramente, nos dados levantados das teses em educação da UNISINOS, a presença, pode-se dizer, da multirreferencialidade e da complexidade, exatamente por meio da mescla de paradigmas. Constatou-se, dentro do período estabelecido para análise, que desde o ano de 2013, há, visivelmente, uma quebra de fronteiras disciplinares.

Como já dito acima, é bem verdade que os autores Guba e Lincoln (1994) destacam, categoricamente, que misturar elementos de um paradigma dentro de outro somente é aceitável quando obedecidos critérios mínimos de convergência axiológica, já que, em razão das diferenças existentes em alguns deles, se comportariam de forma antagônica.

Para eles, com relação à comensurabilidade, pois, é perfeitamente possível mesclar paradigmas positivistas e póspositivistas. Entretanto, para os mencionados autores, com relação à comensurabilidade, o paradigma da teoria crítica e posições ideológicas relacionadas não pode ser mesclado com paradigmas de matriz positivista e pós-positivista, em razão de sua incompatibilidade axiológica, todavia pode apresentar uma comensurabilidade com o paradigma construtivista. Da mesma forma, o paradigma construtivista, quanto à comensurabilidade também não poderia ser mesclada com um dos paradigmas positivista ou pós-positivista, mas apenas com o paradigma da teoria crítica.

Ocorre que da extração dos dados contidos nas tabelas (T1), (T2), (T3), (T4), (T5), (T6) e (T7) abaixo, não é exatamente isso que se observou. Importa destacar, primeiramente, que o paradigma positivista não apareceu uma vez sequer. E se ele não apareceu, a sua única mescla possível, dentro da perspectiva de Guba e Lincoln (1994), qual seja com o paradigma pós-positivista, também não ocorreu, conforme observado a seguir.

A Tabela 1 (T1) a seguir apresenta os resultados referentes aos macro-paradigmas de pesquisa identificados nas teses da UNISINOS defendidas no ano de 2013: 
Tabela 1 (T1): Ocorrência de macro-paradigmas nas teses em 2013.

Total de teses $=18$

\begin{tabular}{lc}
\hline MACRO-PARADIGMAS & OCORRENCIA \\
\hline Teoria Critica / Construtivismo & 15 \\
Teoria Critica / Construtivismo / Pós-Positivismo & 0 \\
Teoria Critica / Pós-Positivismo & 1 \\
Pós-Positivismo / Construtivismo & 2
\end{tabular}

Fonte: Autores (2019).

De acordo com a Tabela 1 (T1), foram analisadas 18 teses de doutorado defendidas no ano de 2013. Em quinze (n=15) pesquisas foi identificada a combinação de paradigmas da Teoria Crítica e do Construtivismo, em nenhuma ( $\mathrm{n}=0$ ) das pesquisas foi identificada a combinação entre os paradigmas da Teoria Crítica, do Construtivismo e do Pós-Positivismo, em uma (n=1) pesquisa foi identificada a combinação entre Teoria Crítica e Pós-Positivismo e em duas (n=2) pesquisas foi identificada a combinação entre os paradigmas do Pós-Positivismo e do Construtivismo.

A Tabela 2 (T2) a seguir apresenta os resultados referentes aos macro-paradigmas de pesquisa identificados nas teses da UNISINOS defendidas no ano de 2014:

Tabela 2 (T2): Ocorrência de macro-paradigmas nas teses em 2014.

Total de teses $=\mathbf{2 0}$

\begin{tabular}{l|c|}
\hline MACRO-PARADIGMAS & OCORRENCIA \\
\hline Teoria Critica / Construtivismo & 14 \\
Teoria Critica / Construtivismo / Pós-Positivismo & 1 \\
Teoria Critica / Pós-Positiviamo & 0 \\
Pós-Positivismo / Construtivismo & 5
\end{tabular}

Fonte: Autores (2019).

De acordo com a Tabela 2 (T2), foram analisadas 20 teses de doutorado defendidas no ano de 2014. Em quatorze $(n=14)$ pesquisas foi identificada a combinação de paradigmas da Teoria Crítica e do Construtivismo, em uma (n=1) das pesquisas foi identificada a combinação entre os paradigmas da Teoria Crítica, do Construtivismo e do Pós-Positivismo, em nenhuma $(n=0)$ pesquisa foi identificada a combinação entre Teoria Crítica e Pós-Positivismo e em cinco ( $\mathrm{n}=5)$ pesquisas foi identificada a combinação entre os paradigmas do Pós-Positivismo e do Construtivismo.

A Tabela 3 (T3) a seguir apresenta os resultados referentes aos macro-paradigmas de pesquisa identificados nas teses da UNISINOS defendidas no ano de 2015:

Tabela 3 (T3): Ocorrência de macro-paradigmas nas teses em 2015.

Total de teses $=23$

\begin{tabular}{l|c}
\hline MACRO-PARADIGMAS & OCORRENCIA \\
\hline Tooria Critica / Construtivismo & 19 \\
Teoria Critica / Construtivismo / Pós-Positivismo & 0 \\
Tooria Critica / Pós-Positivismo & 0 \\
Pós-Positivismo / Construtivismo & 4
\end{tabular}

Fonte: Autores (2019). 
De acordo com a Tabela 3 (T3), foram analisadas 23 teses de doutorado defendidas no ano de 2015. Em dezenove $(n=19)$ pesquisas foi identificada a combinação de paradigmas da Teoria Crítica e do Construtivismo, em nenhuma ( $\mathrm{n}=0)$ das pesquisas foi identificada a combinação entre os paradigmas da Teoria Crítica, do Construtivismo e do Pós-Positivismo, em nenhuma $(n=0)$ pesquisa foi identificada a combinação entre Teoria Crítica e Pós-Positivismo e em quatro ( $\mathrm{n}=4$ ) pesquisas foi identificada a combinação entre os paradigmas do Pós-Positivismo e do Construtivismo.

A Tabela 4 (T4) a seguir apresenta os resultados referentes aos macro-paradigmas de pesquisa identificados nas teses da UNISINOS defendidas no ano de 2016:

Tabela 4 (T4): Ocorrência de macro-paradigmas nas teses em 2016.

Total de teses $=12$

\begin{tabular}{|l|l|}
\hline MACRO-PARADICMAS & OCORAÉNCIA \\
\hline Tooria Critica / Construtivismo & 9 \\
Tooria Critica / Construtivismo / Pós-Positivismo & 2 \\
Tooria Critica / Pós-Positivismo & 0 \\
\hline Pós-Positivismo / Construtivismo & 1 \\
\hline
\end{tabular}

Fonte: Autores (2019).

De acordo com a Tabela 4 (T4), foram analisadas 12 teses de doutorado defendidas no ano de 2016. Em nove (n=9) pesquisas foi identificada a combinação de paradigmas da Teoria Crítica e do Construtivismo, em duas (n=2) das pesquisas foi identificada a combinação entre os paradigmas da Teoria Crítica, do Construtivismo e do Pós-Positivismo, em nenhuma (n=0) pesquisa foi identificada a combinação entre Teoria Crítica e Pós-Positivismo e em uma (n=1) pesquisa foi identificada a combinação entre os paradigmas do Pós-Positivismo e do Construtivismo.

A Tabela 5 (T5) a seguir apresenta os resultados referentes aos macro-paradigmas de pesquisa identificados nas teses da UNISINOS defendidas no ano de 2017:

Tabela 5 (T5): Ocorrência de macro-paradigmas nas teses em 2017.

\section{Total de teses $=14$}

\begin{tabular}{l|c}
\hline MACRO-PARADIGMAS & OCORRENCIA \\
\hline Teoria Critica / Construtivismo & 10 \\
Teoria Critica / Construtivismo / Pós-Positivismo & 2 \\
Teoria Critica / Pós-Positivismo & 0 \\
Pós-Positivismo / Construtivismo & 2
\end{tabular}

Fonte: Autores (2019).

De acordo com a Tabela 5 (T5), foram analisadas 14 teses de doutorado defendidas no ano de 2017. Em dez (n=10) pesquisas foi identificada a combinação de paradigmas da Teoria Crítica e do Construtivismo, em duas (n=2) das pesquisas foi identificada a combinação entre os paradigmas da Teoria Crítica, do Construtivismo e do Pós-Positivismo, em nenhuma (n=0) pesquisa foi identificada a combinação entre Teoria Crítica e Pós-Positivismo e em duas (n=2) pesquisas foi identificada a combinação entre os paradigmas do Pós-Positivismo e do Construtivismo.

A Tabela 6 (T6) a seguir apresenta os resultados referentes aos macro-paradigmas de pesquisa identificados nas teses da UNISINOS defendidas no ano de 2018: 
Tabela 6 (T6): Ocorrência de macro-paradigmas nas teses em 2018.

Total de teses $=16$

\begin{tabular}{lc|}
\hline MACRO-PARADIGMAS & OCORRẼNCIA \\
\hline Teoria Critica / Construtivismo & 11 \\
Teoria Critica / Construtivismo / Pós-Positivismo & 1 \\
Teoria Critica / Pós-Positivismo & 1 \\
Pós-Positivismo / Construtivismo & 3
\end{tabular}

Fonte: Autores (2019).

De acordo com a Tabela 6 (T6), foram analisadas 16 teses de doutorado defendidas no ano de 2018. Em onze (n=11) pesquisas foi identificada a combinação de paradigmas da Teoria Crítica e do Construtivismo, em uma (n=1) das pesquisas foi identificada a combinação entre os paradigmas da Teoria Crítica, do Construtivismo e do Pós-Positivismo, em uma (n=1) pesquisa foi identificada a combinação entre Teoria Crítica e Pós-Positivismo e em três ( $\mathrm{n}=3$ ) pesquisas foi identificada a combinação entre os paradigmas do Pós-Positivismo e do Construtivismo.

Pois bem. Das mesclas não possíveis, para Guba e Lincoln (1994), em razão da incompatibilidade axiológica (Teoria Crítica e Pós-Positivismo e Pós-Positivismo e Construtivismo, ou mesmo Teoria Crítica, Construtivismo e Pós-Positivismo), detectou-se que das 103 teses (100\%), 25 (24,27\%) estabeleceram tais combinações. Por outro lado, a comensurabilidade possível entre o paradigma da teoria crítica e o paradigma construtivista teve a maior ocorrência. Ou seja, das 103 teses (100\%), $78(75,72 \%)$ delas estabeleceram mesclas convergentes em consonância com a perspectiva de Guba e Lincoln (1994). Esse último percentual, definitivamente, representa a ascensão dos paradigmas alternativos, ao longo dos anos, conforme demonstrado na Tabela 7 (T7) abaixo:

Tabela 7 (T7): Ocorrência de macro-paradigmas por ano no quadriênio 2012-2018.

\begin{tabular}{|c|c|c|c|c|c|c|c|}
\hline DESCRICADAO & 2013 & 2014 & 2015 & 2010 & 2017 & 2018 & TOTAL. \\
\hline Teona Cntica / Construtvismo & 15 & 14 & 19 & 9 & 10 & 11 & 78 \\
\hline Teoria Cntica / Construtivismo / Pós. Posatvismo & 0 & 1 & 0 & 2 & 2 & 1 & 6 \\
\hline Teona Cntica / Pogs Pcaituvismo & 1 & 0 & 0 & 0 & 0 & 1 & 2 \\
\hline Pós-Positivieno / Conatuthismo & 2 & 8 & 4 & 1 & 2 & 3 & 17 \\
\hline
\end{tabular}

Fonte: Autores (2019).

Por mais que a grande maioria $(75,72 \%)$ das mesclas realizadas pelos pesquisadores da UNISINOS correspondam, fidedignamente, à comensurabilidade admitida por Guba e Lincoln (1994), não se tem, por certo, como afirmar se a teoria dos autores foi utilizada como uma "bússola" durante a trajetória da investigação ou se foi apenas mera coincidência. Da mesma maneira, não se tem como afirmar que as mesclas “inconciliáveis" na perspectiva Guba e Lincoln (1994), de fato, acarretam um comportamento antagônico, adversarial e inconciliável. Afinal de contas, é uma das teorias sobre paradigmas.

\subsection{As teses de doutorado em educação UNISINOS (2013-2018): os paradigmas alternativos em ascendência}

No tópico anterior, discorreu-se sobre a existência da mescla de paradigmas nas teses de doutorado em educação da UNISINOS, o que reflete a dificuldade de um pesquisador em possuir apenas um olhar sobre o seu objeto de pesquisa. Eis, pois, a multirreferencialidade e a complexidade necessárias em qualquer pesquisa. 
A questão ora aqui tratada diz respeito, de certo modo, a uma superação dos paradigmas clássicos (positivismo e póspositivismo) em detrimento dos paradigmas alternativos (teoria crítica e construtivismo). É claro que, também como já discorrido, essa maleabilidade epistemológica possivelmente é ocasionada pela própria constituição da pesquisa científica do programa da UNISINOS, bem como pela escolha metodológica e teórica realizada nas teses. Não há como saber ao certo, já que não se teve acesso ao manual que estabelece as regras para a formulação das Teses. Na Figura 2 (F2) abaixo, constata-se que mais de 70\% das pesquisas contemplaram, em combinações, os paradigmas da teoria crítica e do construtivismo:

Figura 2 (F2): A superação dos paradigmas clássicos.

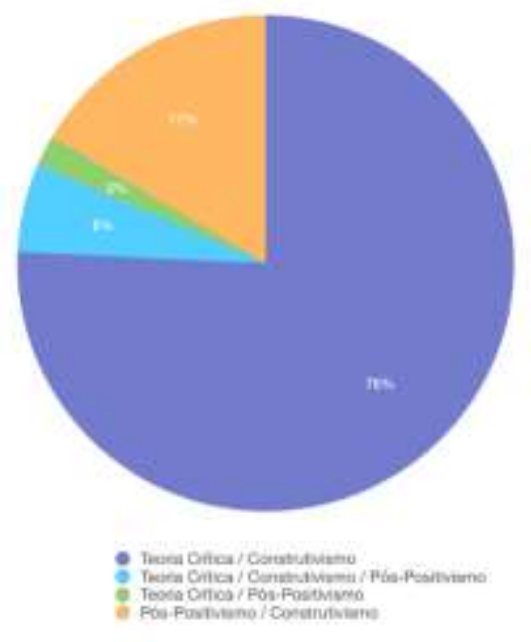

Fonte: Autores (2019).

De acordo com a Figura 2 (F2), em aproximadamente 76\% das teses foi identificada a combinação de paradigmas da Teoria Crítica e do Construtivismo, em aproximadamente 6\% das teses foi identificada a combinação entre os paradigmas da Teoria Crítica, do Construtivismo e do Pós-Positivismo, em aproximadamente 2\% das teses foi identificada a combinação entre Teoria Crítica e Pós-Positivismo e em aproximadamente 17\% das teses foi identificada a combinação entre os paradigmas do Pós-Positivismo e do Construtivismo.

Ou seja, além de uma mescla de paradigmas, há, uma predominância dos paradigmas alternativos, assim chamados por Guba e Lincoln (1994), surgidos em razão da crescente insatisfação com a ênfase excessiva nos métodos quantitativos. E aí o que se pode deduzir é que a categoria "neutralidade", elemento caracterizador do positivismo e pós-positivismo seja, de fato, raro (ou mesmo impossível) de ser alcançado nas ciências humanas.

Afinal de contas, "o pesquisador (mesmo nas exatas) não se situa enquanto elemento exterior, indiferente, numa espécie de 'tanto faz esse ou aquele tema'. E quando isso ocorre, o pesquisador trabalha apenas por trabalhar: cumprir contratos ou mostrar produção" (Borba, 2001, p. 64). "Mais que geômetras, espaços do lógico e da emoção aparente e falsamente controlada, é necessário sermos saltimbancos, espaços das emoções, da arte-anárquica e da complexidade" (Borba, 2001, p. 126). Ao longo do tempo, centenas de cientistas de diversos campos têm discutido a questão da objetividade científica e a relação sujeito-objeto:

Percebemos que o fazer epistêmico, o fazer ciência, tem, nas suas bases, um 'julgamento de valor', ou seja, 'o universal'. É considerado mais satisfatório do que o particular, o mundo do positivismo. Nesse fazer ciência positivista, a subjetividade não tem direito à cidadania. Aí temos dissimulada a vontade de potência e, nela, a de onipotência (cujo luto precisamos trabalhar sempre) (Borba, 2001, p. 65). 
Pesquisa sem objeto, de fato, não existe. Até aí, tudo bem. Mas, os objetos não falam por si. "Para pesquisar, temos que interpretar; na verdade, para viver, temos que interpretar" (Kincheloe, 2007, p. 44). Das Figuras 3 e 4 (F3 e F4) abaixo, observou-se, claramente, que os paradigmas alternativos estão em ascensão no PPGE analisado:

Figura 3 (F3): paradigmas alternativos em ascensão.

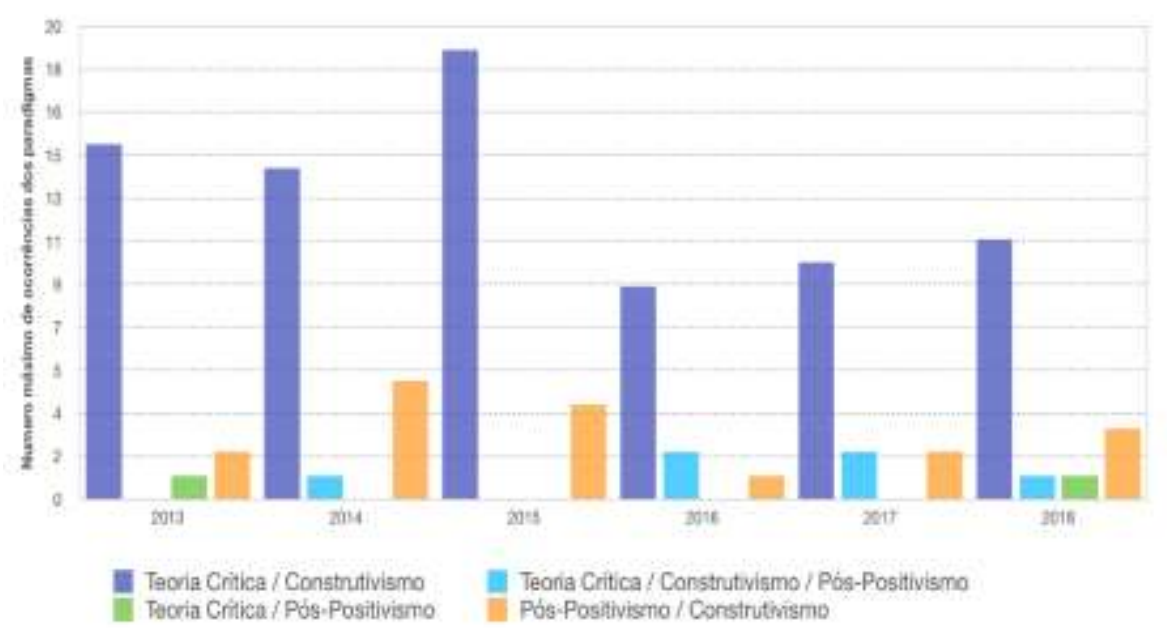

Fonte: Autores (2019).

Figura 4 (F4): A predominância da Teoria Crítica/ Construtivismo nas pesquisas em Educação.

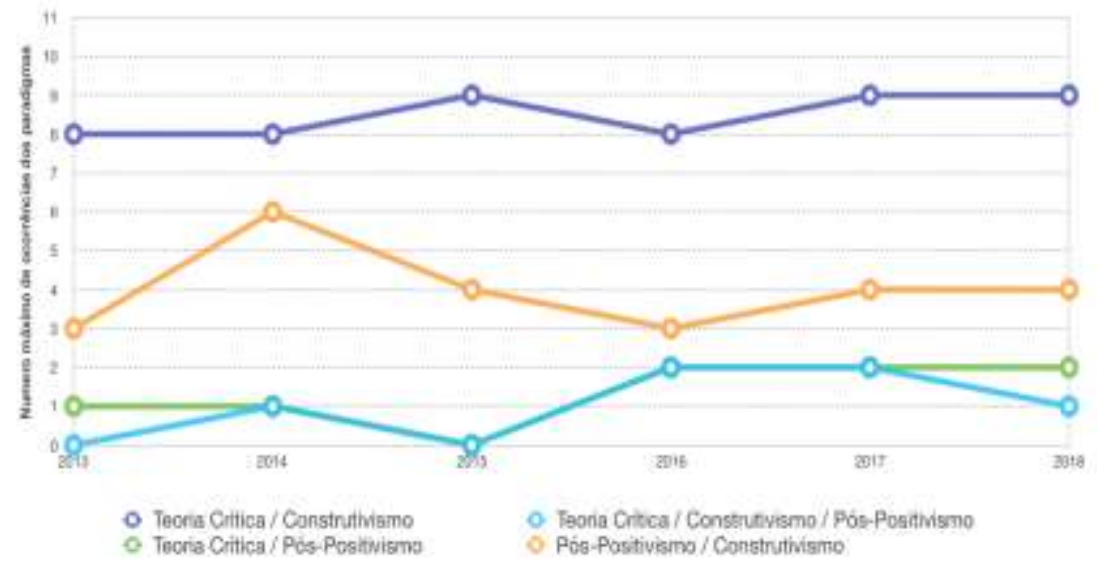

Fonte: Autores (2019).

Essa ascensão dos paradigmas alternativos é natural, na medida em que, principalmente, com os construtivistas, a realidade é reconstruída com base em novas perspectivas. Ou seja, mesmo em busca de um consenso, os construtivistas sempre estão abertos a novas interpretações da realidade. Desse modo, o curso natural do conhecimento é respeitado, uma vez que é construído por meio de múltiplos olhares acerca de um fenômeno. Além disso, essas construções estão sujeitas a contínuas revisões e mudanças em razão da dialética que é uma característica marcante desse tipo de postura investigativa.

\section{Considerações Finais}

Ao longo do tempo, centenas de cientistas de diversos campos têm discutido a questão da objetividade científica e a relação sujeito-objeto. Essa análise perpassa, necessariamente, pela concepção de paradigma. 
Cento e três teses de doutorado em educação da UNISINOS, produzidas no período de 2013 a 2018, tiveram as seções Resumo e Capítulo Metodológico (ou equivalente) analisadas tomando como base os quatro paradigmas estabelecidos por Guba e Lincoln (1994).

Logo se constatou que nenhum dos quatro paradigmas, estabelecidos pelos referidos autores, se apresentou de forma pura, isolada. Ou seja, há, em 100\% das teses de doutorado da UNISINOS (2013-2018), uma mescla de, pelo menos, dois paradigmas. E, de um certo modo, o que se entendeu é que esse fenômeno ocorreu em razão da generalização estabelecida pelos próprios autores, Guba e Lincoln (1994).

É claro que o fato de não ter encontrado, de forma pura e isolada um paradigma em cada tese, não significa dizer, por certo, que não seja possível encontrá-lo em pesquisas científicas. Ademais, mesmo detectando a presença de mais de um paradigma, também não foi possível identificar qual deles tiveram a maior ou a menor incidência. Eis uma limitação temporal que essas pesquisadoras tiveram que lidar. Contudo, a ocorrência da mescla de paradigmas foi, sem dúvida, um importante guia para a análise dos dados.

Percebeu-se, nitidamente, que os pesquisadores da UNISINOS se apoiam numa multiplicidade de paradigmas para o desenvolvimento de suas pesquisas. É claro que essa maleabilidade epistemológica caracterizada por meio da mescla de paradigmas pode ocorrer em razão da própria constituição da pesquisa científica do programa da UNISINOS, como também pela escolha metodológica e teórica realizada nas teses. Mas, certamente, esse cenário reflete uma reflexão importante entre os paradigmas, o objeto de pesquisa e o pesquisador, qual seja a consolidação da multirreferencialidade nas pesquisas científicas.

$\mathrm{E}$, independente se as mesclas seguiram ou não as combinações por compatibilidade axiológica de Guba e Lincoln (1994), há uma quebra de fronteiras disciplinares. Pois bem. Dessas mesclas não cabíveis na concepção de Guba e Lincoln (1994) por incompatibilidade axiológica (Teoria Crítica e Pós-Positivismo e Pós-Positivismo e Construtivismo, ou mesmo Teoria Crítica, Construtivismo e Pós-Positivismo), detectou-se que das 103 teses (100\%), 25 (24,27\%) estabeleceram tais mesclas, com a ressalva de que o paradigma positivista não apareceu uma vez sequer. Mas, em relação a comensurabilidade possível entre o paradigma da teoria crítica e o paradigma construtivista, 78 (75,72\%) das teses estabeleceram mesclas convergentes em consonância com a perspectiva de Guba e Lincoln (1994), o que denota a ascensão dos paradigmas alternativos.

É bem verdade que, por mais que a grande maioria $(75,72 \%)$ das mesclas realizadas pelos pesquisadores da UNISINOS correspondam, fidedignamente, à comensurabilidade admitida por Guba e Lincoln (1994), não se pode afirmar se a teoria dos referidos autores foi utilizada como base teórica durante a trajetória da investigação ou se foi apenas mera coincidência. Da mesma maneira, não se tem como afirmar que as mesclas "inconciliáveis" na perspectiva Guba e Lincoln (1994), de fato, acarretam um comportamento antagônico, adversarial e inconciliáveis. Afinal de contas, é apenas uma teoria...

O que se almeja, principalmente em educação, é que as pesquisas abracem sempre novas perspectivas e novas interpretações para a reconstrução da realidade. $O$ que se espera é que os pesquisadores respeitem o curso natural do conhecimento. O que se deseja é que um fenômeno seja observado por múltiplos olhares. O que se sonha, ao final, é que as construções sejam continuamente revistas e transformadas em razão da dialética, característica primordial da postura um pesquisador.

Por fim, esse trabalho aspira despertar em outros pesquisadores a curiosidade pela axiologia da construção do conhecimento científico, ampliando a gama de investigação para que possamos expandir nosso diálogo através da produção acadêmica. 
Research, Society and Development, v. 11, n. 1, e53611125219, 2022

(CC BY 4.0) | ISSN 2525-3409 | DOI: http://dx.doi.org/10.33448/rsd-v11i1.25219

\section{Referências}

Altmicks, A. F. (2014) Principais paradigmas da pesquisa em Educação realizada no Brasil. Revista Contrapontos,14(2), 384-397.http://doi: 10.14210/contrapontos.v14n2.p384-397.

Bauer, M. W., \& Gaskell, G. (2015). Pesquisa qualitativa como texto, imagem e som: um manual prático (13a ed.), Vozes

Borba, S. C. (2001). Multirreferencialidade: na formação do “professor-pesquisador”: da conformidade à complexidade (2a ed), EDUFAL.

Creswell, J. W. (2010). Projeto de pesquisa: métodos qualitativo, quantitativo e misto (3a ed.). Artmed.

Creswell, J. W., \& Clark, V. L. P. (2013). Pesquisa de Métodos Mistos (2a ed). Penso.

Creswell, J. W., \& Creswell, J. D. (2018). Research Design: qualitative, quantitative and Mixed Methods Approaches (5a ed). Sage Pulblications.

Crotty, M. (1998). The Foundations of Social Research: Meaning and Perspective in the Research Process. SAGE Publications.

Delgado, J. de S. \& Kölling, G. J. (2021). O avanço comunitário do ensino e da pesquisa para a universidade do amanhã. Revista Direitos Culturais, 16(40), 307-320. https://doi.org/10.20912/rdc.v16i40.639.

Fontana, F. (2018). Técnicas de pesquisa. In: T. Mazucato (org). Metodologia da pesquisa e do trabalho científico. FUNEPE.

Gil, A.C (2019). Como elaborar projetos de pesquisa. (6a ed.), Atlas.

Gil, A.C. (2021). Como fazer pesquisa qualitativa. Atlas.

Guba, E. G. \& Lincoln, Y. S. (1994). Competing paradigms in qualitative research. In N. K. Denzin \& Y. S. Lincoln (orgs.). Handbook of qualitative research (105-117). Sage Publications.

Kuhn, T. S. (1970). The structure of scientific revolutions (2a ed), University of Chicago Press.

Kincheloe, J. L. (2007). O poder da bricolagem: ampliando os métodos de pesquisa. In: J.L. Kincheloe \& K.S. Berry (orgs.). Pesquisa em bricolagem: conceituando a bricolagem (15-37). Artmed.

Nascimento Sandes, F., \& da Silva, C. (2021). Ciência, paradigmas científicos e inter/transdisciplinaridade: implicações pedagógicas. Horizontes, 39(1), e021060. https://doi.org/10.24933/horizontes.v39i1.1134

Neto, A L B. (2020) A dialética das tradições de pesquisa de Alasdair Macintyre. Griot. Revista de Filosofia, 20 (1), 314-338. https://doi.org/10.31977/grirfi.v20i1.1448

Newman, J. M. (2000). Action research: A brief overview. Forum: Qualitative Social Research, 1(1). https://doi.org/10.17169/fqs-1.1.1127

Oliveira M.M. (2016). Como fazer pesquisa qualitativa (7a ed.), Vozes.

Pires, C. S., \& Veiga, A. M. da R. (2020). Sewing possibilities in the complexity of teaching: bricolage in the auto (trans) formative trajectory. Research, Society and Development, 9(9), e20996496. https://doi.org/10.33448/rsd-v9i9.6496

Rossi, E. R. (2021). Inovações educacionais no tempo presente e rupturas no paradigma moderno: uma análise das pesquisas educacionais da Universidade de Genebra. Educar em Revista, Curitiba, 37, e78885. https://doi.org/10.1590/0104-4060.78885

Saccol, A. Z (2009). Um retorno ao básico: compreendendo os paradigmas de pesquisa e sua aplicação na pesquisa em administração. Revista de Administração da UFSM, 2(2), 250-269. https://doi.org/10.5902/198346591555

Sampierre, R. H., Colado \& C. F., Lucio, P. B. (2013). Metodologia de Pesquisa. (5a ed.), Penso.

Santos, L. (2002, setembro). A investigação e os seus implícitos: contributos para uma discussão. In Anais do VI Simpósio de la SEIEM, Logroño, Espanha.

Silva, S. A. (2012). O que é um paradigma? Revista de Ciências Humanas, 45 (2), 345-354. https://doi.org/10.5007/2178-4582.2011v45n2p345

Stake, R. E (2011). Pesquisa qualitativa: estudando como as coisas funcionam. Grupo A

Strauss, A. \& Corbin, J. (2008). Pesquisa qualitativa: Técnicas e procedimentos para o desenvolvimento da teoria fundamentada. (2a ed), Artmed.

Yin, R. K. (2016). Pesquisa qualitativa do início ao fim. Penso. 